\title{
Estudo da Radiação na areia da praia das Castanheiras
}

\author{
Calheiro, D.S. ${ }^{1 *}$; Passamai, Jr.J.L. ${ }^{1}$; Orlando, M. T. D. ${ }^{2}$ \\ 1 Departamento de Química e Física, Universidade Federal do Espírito Santo, Alegre, ES, Brasil. \\ 2 Departamento de Física, Universidade Federal do Espírito Santo, Vitória, ES, Brasil.
}

* e-mail: danielcalheiro@gmail.com

\section{Resumo}

Nesse estudo temos o objetivo de fazer o levantamento da medida da radioatividade na faixa de areia utilizada pelos banhistas da praia das Castanheiras em Guarapari/ES, foi constatado que a areia apresenta medidas de radioatividade mais concentradas nas suas extremidades. Para a realização das medidas foram utilizado um contador Geiger e um ciclocomputador, pode-se concluir que existe uma movimentação da radiação durante os meses do ano ao longo de toda praia.

\begin{abstract}
In this study we aim to take stock of the radioactivity measured in the strip of sand used for beach bathers Castanheiras in Guarapari / ES, it was found that the sand has more concentrated radioactivity measures at their ends. For the measurements were used a Geiger counter, and a cycling computer, it can be concluded that there is a movement of radiation during the months of the year along the entire beach.
\end{abstract}

Keywords (Palavras chaves): Monazita, Radioatividade, Óxido de Tório.

\section{Introdução}

No presente trabalho foi feito medição da radioatividade da areia da praia das Castanheiras. Foi observado a olho nu a faixa escura de areia (monazita) que continha a radioatividade foi movimentada pela maré ao longo de toda faixa de areia utilizada pelos banhistas.

Nós utilizamos o sentido de mediação sempre norte-sul, foi possível fazer as medidas a cada 15 dias aproximadamente durante os meses de Março de 2016 até Maio de 2016.

\section{Apresentação dos resultados}

Após a primeira medida realizada, foi feita foi possível constatar que tivemos picos de intensidade próximo de $5 \mathrm{~Bq}$ na distância de aproximadamente 400 metros e 460 metros, isto é, próximo ao clube siribera.

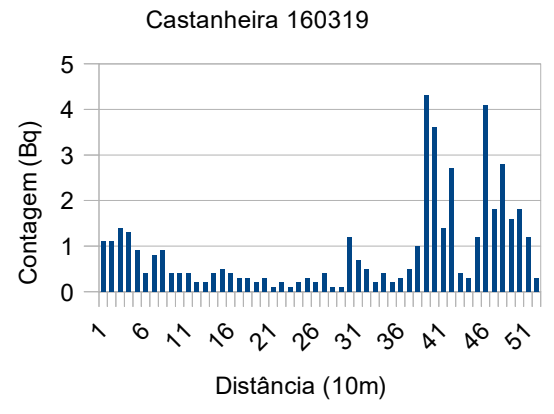

A próxima medida foi realizada e foi possível medir uma diminuição da radioatividade para próximo de 2,5 Bq no final da praia.

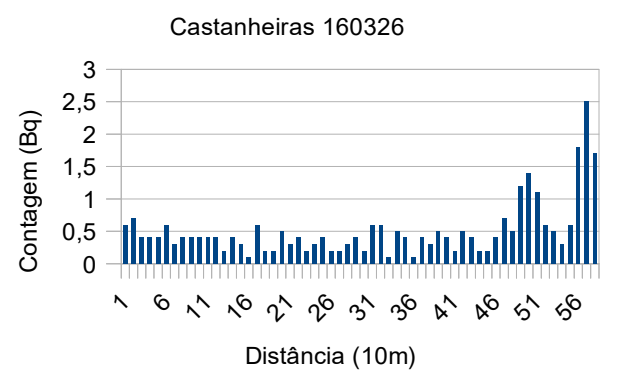


A medida realizada em 16.04.2016 foi constatada que a concentração de material radioativo voltou a subir próxima à distância de 400 metros. Podemos notar que até a presente medida a região que fica atrás das pedras localizadas próximo ao centro da praia das castanheiras variou muito pouco.

Castanheiras_160416

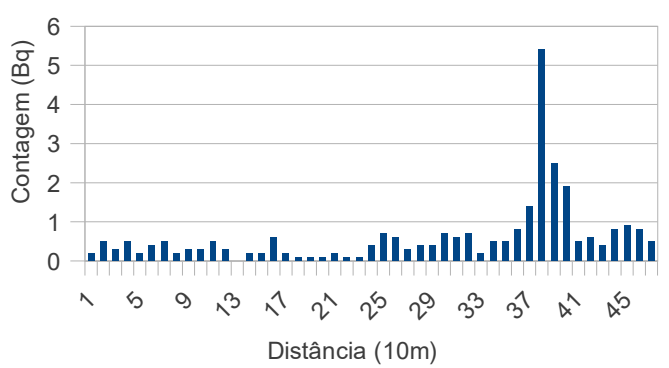

Fizemos a medida em 30.04.2016 e foi medida uma diminuição na intensidade da radiação próxima ao final da praia, podemos notar que no início da praia a radiação não variou muito desde o início das medidas.

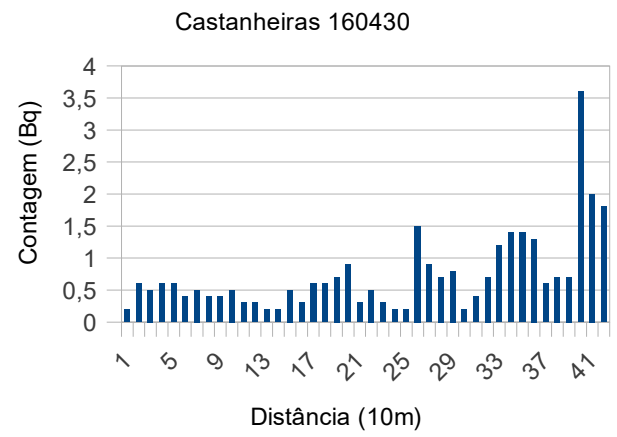

$\mathrm{Na}$ próxima medida foi realizada foi verificado um acréscimo de radiação em aproximadamente 260 metros, esta região compreende a faixa de areia utilizada pelos banhistas atrás das pedras no centro da praia, provavelmente uma movimentação da radiação devido à alta da maré e diminuição dos segundos e terceiros picos.

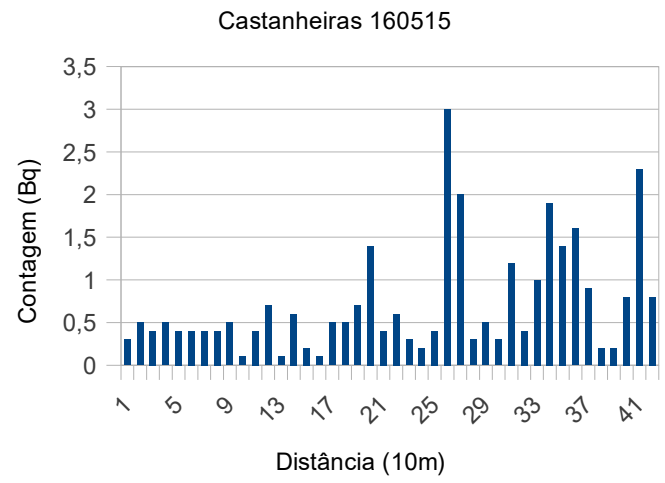

Verificamos na medida seguinte uma diminuição da radiação nos picos mencionados anteriormente e um aumento da radiação no final da praia. Notamos também que a região próxima ao centro da praia houve uma diminuição.

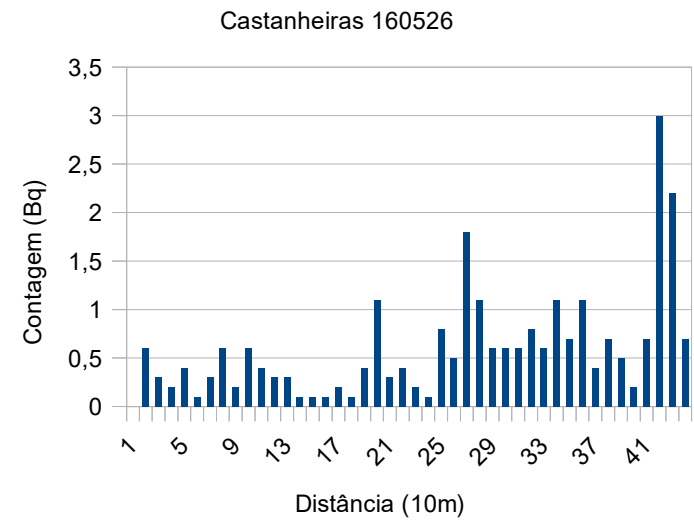

\section{Conclusões}

Em nossos estudos estão sendo verificados que a elementos radioativos misturados com a areia está claramente se movimentando pela faixa de areia utilizada pelos banhistas e que a maré que atua na praia das castanheiras é uma das responsáveis por esse movimento, juntamente com a ação dos ventos, estes estão sendo surpreendentes, pois não tínhamos dados anteriores que areia com material radioativo se movimentava com tanta rapidez nos intervalos de aproximadamente 15 dias entre as medidas.

\section{Referências}

FUJINAMI, N.; T. KOGA, T.; MORISHIMA. H. EXTERNAL EXPOUSURE RATES FROM TERRESTRIAL RADIANTION AT GUARAPARI AND MEAIPE IN BRAZIL. 1999.

VASCONCELOS, D.C, et al. MODELLING NATURAL RADIOACTIVITY IN SAND BEACHES OF GUARAPARI, ESPÍRITO SANTO STATE, BRAZIL. 2013 